\title{
Effect of anticholinergic burden on the onset of delirium in elderly hospitalized patientsassessed by 3 anticholinergic scales
}

NGOMBENZALE GOY ( $\nabla$ edith.goy@gmail.com )

Erasme Hospital: Hopital Erasme

JESSICA EPOUPA

Erasme Hospital: Hopital Erasme

JEAN-CHRISTOPHE BIER

Erasme Hospital: Hopital Erasme

GILLES NAEIJE

Erasme Hospital: Hopital Erasme

LAETITIA BEERNAERT

Erasme Hospital: Hopital Erasme

CAMILLE NICOLAY

Erasme Hospital: Hopital Erasme

SANDRA DE BREUCKER

Erasme Hospital: Hopital Erasme

\section{Research article}

Keywords: Delirium, elderly, anticholinergic burden

Posted Date: March 2nd, 2021

DOI: https://doi.org/10.21203/rs.3.rs-279516/v1

License: (a) (i) This work is licensed under a Creative Commons Attribution 4.0 International License. Read Full License 


\section{Abstract}

Background: Several studies have demonstrated the deleterious effects of anticholinergic drugs on the cognitive functions of the elderly. However, their effects on the onset of delirium have produced conflicting results. We assessed the association of the anticholinergic burden of treatment at admission according to 3 anticholinergic scales, the ADS, the modified ADS (mADS) and the Marante Scale on the onset of delirium in elderly hospitalized patients. We also analyzed the inter-rater reliability of the scales and their prognostic value in terms of length of stay and hospital mortality.

Methods: This retrospective study included patients over 75 years of age hospitalized in medical and surgical departments between January 2014 and June 2019. Delirium was diagnosed by the Confusion Assessment Method (CAM). The anticholinergic burden was assessed by ADS, mADS and Marante Scale in patients with and without delirium.

Results were reported as percentages for categorical variables and mean \pm standard deviation (SD) and median [interquartile range] for continuous variables after Kolmogorov-Smirnov distribution test.

Descriptive statistics were performed using paired Student t-test or Chi-square test. Spearman's correlation was run to assess the inter-rater reliability between ADS, mADS and the Marante Scale.

Results: Among the 1487 patients included, 26\% developed delirium. No statistically significant difference in anticholinergic burden was observed between the delirium group and the control group, regardless of the anticholinergic scale used. The correlation coefficient was respectively 0.35 and 0.33 between ADS, mADS and the Marante Scale, and 0.97 between ADS and mADS (all $p<0.001$ ). None of the three scales were associated with length of stay, intra-hospital mortality, or one-year mortality. In multivariate analysis, ADS and mADS scores were independently associated with depression ( $p=0.003$ and $<0.0001)$, drug withdrawal (both $p<0.001$ ) and the number of drugs on admission (both $p<0.001$ ), and Marante Scale score was independently associated with living in a nursing home $(\mathrm{p}=0.018)$ and the number of drugs on admission $(p<0.0001)$.

Conclusions: Regardless of the scale used, we did not demonstrate a significant association between the anticholinergic burden of treatment upon admission and the onset of delirium during hospitalization.

\section{Background}

According to DSM-IV criteria, delirium is an acute neurocognitive disorder characterized by a transient and fluctuating disturbance of cognition with decreased ability to concentrate and maintain attention ${ }^{1}$. Delirium is often under-diagnosed and is associated with loss of autonomy, lengthened hospital stays and increased hospital mortality 2,3 . The prevalence of delirium ranges from 14 to $24 \%$ in hospitalized patients, and mortality may reach $76 \%{ }^{4}$. Etiology is often multifactorial and results from the interaction between predisposing and precipitating factors ${ }^{1,5,6}$. Predisposing factors like the history of dementia represents the patient's vulnerability, while precipitating factors are defined as harmful elements or hospitalization related factors that contribute to the development of delirium, such as surgery or drug withdrawal. Although the 
pathophysiology has not yet been fully elucidated, a deficiency in acetylcholine, involved in the process of memory and attention, has been observed ${ }^{7,8}$. In addition to a decreased renal and hepatic drug elimination and polypharmacy, this cholinergic deficiency can be worsened by drugs with anticholinergic effect, exposing older people to an increased risk of adverse effects ${ }^{9,10}$.

The cumulative effect of multiple drugs with anticholinergic properties is called Anticholinergic Burden (AB), which is assessed by the serum anticholinergic activity (SAA) of drugs, based on drug's affinity for the muscarinic acetylcholine receptor, with atropine being the reference molecule ${ }^{11}$. As this method is not applicable in clinical practice, several authors developed tools to assess anticholinergic burden, such as Anticholinergic Drug Scale (ADS) which predicts partly the SAA (R2 $=.0947, \mathrm{p}<.0001)^{12}$ and corresponds to the sum of the anticholinergic load values of each drug taken by the patient at admission, modified ADS (mADS) which corresponds to the sum of the anticholinergic load values of each drug upon admission according to the ADS multiplied by the ratio of the daily dose and the minimum recommended dose ${ }^{13}$, and Muscarinic Acetylcholinergic Receptor Antagonist Exposure (MARANTE) Scale, recently validated on a Belgian population, which combines the anticholinergic potency of the drug and its dosage $\mathrm{e}^{14}$.

According to the literature, none of these scales is currently recommended for predicting the risk of delirium in hospitalized elderly patients ${ }^{12,15}$. Furthermore, the association between anticholinergic burden and delirium has given conflicting results ${ }^{12,15,16}$.

The aim of our study was to assess the predictive value of the anticholinergic burden at hospital admission according to ADS, modified ADS and Marante Scale on the onset of delirium. We also evaluated other factors associated with delirium, inter-rater reliability of the scales and their prognostic value in terms of length of stay and hospital mortality.

\section{Methods}

\section{Study design}

This retrospective study was conducted at the Erasme University Clinics in Brussels between January 2014 and June 2019 after approval of the institutional ethical committee (August 6th, reference P2019 /379). It included patients over 75 years of age hospitalized in different medical and surgical departments, where they are systematically screened and assessed for geriatric syndromes by the Geriatric Internal Liaison team (GILT). It excepts geriatric, intensive care and emergency units.

Data were recorded by two nurses in geriatrics and monitored by a trained geriatrician. Each medication for wich there was a doubt about how to score the anticholinergic burden was discussed.

Delirium was diagnosed using the Confusion Assessment Method (CAM) ${ }^{17}$ during hospitalization. CAM is regularly performed by nurses in the 24 hours after admission, following a standard operating procedure. Demographic and social characteristics, co-morbidity (according to CIRS-G ${ }^{18}$ ) and geriatric syndromes such as loss of autonomy (Katz scale ${ }^{19}$ ), depression $\left(\right.$ GDS-4 items ${ }^{20}$ ), cognitive impairment (Minimal Mental 
State Examination, $\mathrm{MMSE}^{21}$ ) and polypharmacy (from the medical list of the patient's usual medication at home) were identified. Predisposing factors for delirium such as sensory deprivation, alcohol abuse, history of stroke, history of dementia and delirium as well as precipitating factors such as drug withdrawal or surgery were also analyzed.

The anticholinergic burden was assessed using three anticholinergic scales: ADS, mADS and Marante scale which corresponds to the sum of the anticholinergic burden values of each drug upon admission (as listed by Duran et al. ${ }^{23}$ ) multiplied by the ratio of the daily dose and the recommended dose.

\section{Statistics}

Categorical variables were expressed in percentage, continuous variables in means \pm standard deviation (SD) if the distribution was normal, or in medians interquartile ranges [25-75] if the distribution was nonparametric, according to the Kolmogorov-Smirnov test. Groups with and without delirium were compared using Fischer's Chi-square test for categorical variables, Student's t-test for continuous variables with normal distribution and Mann Whitney's test for continuous variables with non-normal distribution. The statistical significance level was set at a p-value of less than 0.05. Spearman's correlation was run to assess the interrater reliability between ADS, mADS and the Marante Scale. single linear regression and then multivariable linear regression analysis were performed to analyze the association between anticholinergic scales and the length of stay and mortality; and to analyze the variables associated with delirium, using the backward regression. All statistical tests were performed using STATA 12.0 software, Lakecorp, Texas, USA.

\section{Results}

The original cohort included 3673 patients (Fig. 1) whom 1573 patients were not evaluated, our sample being representative of the whole population for age, sex and prevalence of delirium. We excluded duplicates, patients under 75 years, patients with missing records, incorrectly sampled or incorrect assessment date.

Of the 1487 patients remaining, 388 (26\%) developed delirium during their hospitalization. The median age of the whole group was 84 [77-87] years and more than half were women. The characteristics of delirium group and control group are described in Table 1. In comparison to the control group, patients with delirium were more frequently men, more often from nursing homes, and had a longer length of stay. Intra-hospital mortality and one-year mortality were significantly higher in patients with delirium. These patients also had more comorbidities and were more dependent on basic activities of daily living. With the exception of depression and history of stroke, factors predisposing and factors precipitating delirium were more common in the delirium group. 
Table 1

Baseline characteristics of study participants

$\begin{array}{lll}\text { Total group } & \text { Delirium } & \text { No delirium } \\ (n=1487) & (n=388) & (n=1099)\end{array}$

Demographic data

Age (years)

84 [80-87]

84 [80-88]

$84[80-87]$

0.422

Female sex $\mathrm{n}(\%)$

$852(57)$

$198(51)$

$654(60)$

0.003

Place of life $n(\%)$

$1128(76)$

277 (72)

851 (78)

0.021

Home

$355(24)$

109 (28)

$246(22)$

Nursing home

Length of stay (days)

11 [7-19]

15 [9-24]

$11[7-17]$

$<0.001$

Intra-hospital mortality $\mathrm{n}(\%)$

105 (7)

53 (14)

$52(5)$

$<0.001$

One-year mortality n(\%)

$450(30)$

144 (37)

$306(28)$

$<0.001$

\section{Geriatric data}

ADL (Katz) (pts/24)

CIRS-G (pts/56)

11 [7-16]

12 [7-18]

$10[7-16]$

$<0.001$

11 [8-15]

12 [9-16]

$11[8-14]$

0.002

\section{Drug data}

$\mathrm{Nr}$ of drugs on admission

$7[5-10]$

$7[4-10]$

7 [5-10]

0.183

ADS (pts)

0 [0-1]

0 [0-1]

0 [0-1]

0.993

mADS (pts)

0 [0-2]

0 [0-2]

0 [0-2]

0.907

Marante Scale (pts)

1.5 [1-2.5]

$1.5[1-3]$

$1.5[1-2.5]$

0.782

\section{Factors predisposing delirium}

History of delirium $\mathrm{n}(\%)$

Depression $\mathrm{n}(\%)$

Sensory deprivation $\mathrm{n}(\%)$

History of stroke $\mathrm{n}(\%)$

History of dementia n(\%)

MMSE (pts/30)
364 (25)

731 (51)

514 (35)

$292(20)$

$628(42)$

24 [20-27]
$132(34)$

$181(51)$

$155(40)$

$83(21)$

$233(60)$

23 [18-25]
$232(21)$

$<0.001$

550 (52)

0.770

359 (33)

0.010

209 (19)

0.323

395 (33)

0.010

25 [20-28]

$<0.001$

ADL: Activities of Daily Living - CIRS-G: Cumulative Illness Rating Scale - ADS: Anticholinergic Drug Scale - mADS: modified anticholinergic drug scale - Marante scale: Muscarinic Acetylcholinergic Receptor Antagonist Exposure - MMSE: Minimal Mental State Examination 


\begin{tabular}{|c|c|c|c|c|}
\hline & Total group & Delirium & No delirium & p \\
\hline Alcohol abuse n(\%) & $108(7)$ & $39(10)$ & $69(6)$ & 0.013 \\
\hline \multicolumn{5}{|c|}{ Factors precipitating delirium } \\
\hline Drug withdrawal n(\%) & $282(19)$ & $98(25)$ & $184(17)$ & $<0.0001$ \\
\hline Surgery $n(\%)$ & $225(15)$ & $80(21)$ & $145(13)$ & $<0.001$ \\
\hline
\end{tabular}

According to ADS and mADS scores, $49 \%$ patients of the total group were taking drugs with an anticholinergic effect and $45 \%$ according to Marante Scale.

Regardless of the scale, we didn't find any statistically significant difference in anticholinergic burden between the delirium group and the control group (Table 1).

We observed a strong positive correlation between ADS and mADS (Spearman's rho 0.97, $p<0.0001$ ), but a moderate positive correlation between ADS, mADS and the Marante Scale (Spearman's rho respectively 0.33 and $0.35, p<0.0001)$.

All scores of all the three anticholinergic burden scales were positively associated with living in nursing homes, with comorbidity, and with the number of drugs on admission. Scores of ADS and mADS were associated with female sex, ADL, depression and drug withdrawal. mADS was associated with sensory deprivation and Mini Mental State score.

No score of the three scales was associated with the length of stay, intra-hospital mortality, or one-year mortality. The results are summarized in Table 2. 
Table 2

Univariate linear regression analysis of ADS, mADS and Marante Scale
ADS
mADS
Marante

$\begin{array}{lllllllll}\text { coeff } & 95 \% \mathrm{Cl} & \mathrm{p} & \text { coeff } & 95 \% \mathrm{Cl} & \mathrm{p} & \text { coeff } & 95 \% \mathrm{Cl} & \mathrm{p}\end{array}$

\section{Demographic data}

\begin{tabular}{|c|c|c|c|c|c|c|c|c|c|}
\hline Age & -0.007 & $\begin{array}{l}-0.02- \\
0.04\end{array}$ & 0.230 & -0.008 & $\begin{array}{l}-0.025- \\
0.008\end{array}$ & 0.329 & -0.01 & $\begin{array}{l}-0.03- \\
0.005\end{array}$ & 0.153 \\
\hline $\begin{array}{l}\text { Sex }= \\
\text { female }\end{array}$ & -0.29 & $\begin{array}{l}-0.42- \\
-1.69\end{array}$ & $\hat{0.001}$ & -0.39 & $\begin{array}{l}-0.57- \\
-0.20\end{array}$ & $\hat{0} .001$ & -0.07 & $\begin{array}{l}-0.27- \\
0.13\end{array}$ & 0.495 \\
\hline $\begin{array}{l}\text { Place of } \\
\text { life }=\end{array}$ & 0.078 & $\begin{array}{l}0.006- \\
1.49\end{array}$ & 0.033 & 0.35 & $\begin{array}{l}0.17- \\
0.53\end{array}$ & <.001 & 0.27 & $\begin{array}{l}0.10- \\
0.44\end{array}$ & 0.002 \\
\hline
\end{tabular}

nursing

home

$\begin{array}{llllllllll}\begin{array}{l}\text { Length of } \\ \text { stay }\end{array} & -0.002 & \begin{array}{l}-0.006- \\ 0.01\end{array} & 0.163 & -0.003 & \begin{array}{l}-0.008- \\ 0.002\end{array} & 0.283 & -0.005 & \begin{array}{l}-0.013- \\ 0.004\end{array} & 0.273 \\ \begin{array}{l}\text { Inhospital } \\ \text { mortality }\end{array} & -0.02 & \begin{array}{l}-0.12- \\ 0.08\end{array} & 0.676 & -0.02 & \begin{array}{l}-0.17- \\ 0.12\end{array} & 0.739 & -0.015 & \begin{array}{l}-0.12- \\ 0.091\end{array} & 0.781 \\ \begin{array}{l}\text { One-year } \\ \text { mortality }\end{array} & 0.012 & \begin{array}{l}-0.11- \\ 1.31\end{array} & 0.839 & 0.13 & \begin{array}{l}-0.07- \\ 0.34\end{array} & 0.191 & 0.04 & \begin{array}{l}-0.17- \\ 0.25\end{array} & 0.692 \\ \end{array}$

Geriatric data

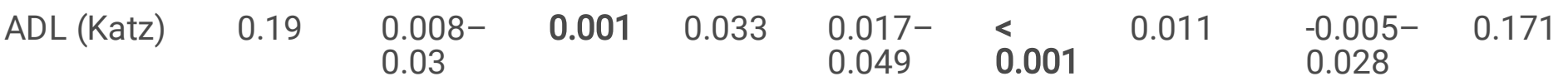

$\begin{array}{llllllllll}\text { Comorbidity } & 0.028 & 0.015- & < & 0.04 & 0.02- & < & 0.036 & 0.016- & 0.001 \\ \text { (CIRS-G) } & & 0.41 & 0.001 & & 0.06 & 0.001 & & 0.57 & \end{array}$

$\begin{array}{llllllllll}\text { Delirium } & -0.015 & \begin{array}{l}-0.16- \\ 1.28\end{array} & 0.833 & 0.022 & \begin{array}{l}-0.19- \\ 0.23\end{array} & 0.837 & 0.19 & \begin{array}{l}-0.02- \\ 0.4\end{array} & 0.082 \\ & & & & & & 0.19\end{array}$

\section{Drugs data}

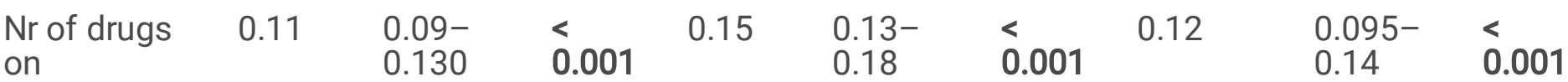

admission

\section{Factors predisposing delirium}

\begin{tabular}{|c|c|c|c|c|c|c|c|c|c|}
\hline $\begin{array}{l}\text { History of } \\
\text { delirium } \\
\mathrm{n}(\%)\end{array}$ & -0.003 & $\begin{array}{l}-0.09- \\
-0.01\end{array}$ & 0.956 & 0.05 & $\begin{array}{l}-0.09- \\
0.19\end{array}$ & 0.479 & -0.05 & $\begin{array}{l}-0.16- \\
0.056\end{array}$ & 0.351 \\
\hline $\begin{array}{l}\text { Depression } \\
\mathrm{n}(\%)\end{array}$ & 0.35 & $\begin{array}{l}0.22- \\
0.47\end{array}$ & $<.001$ & 0.59 & $\begin{array}{l}0.41- \\
0.77\end{array}$ & ¿.001 & 0.17 & $\begin{array}{l}-0.034- \\
0.37\end{array}$ & 0.103 \\
\hline
\end{tabular}




\begin{tabular}{|c|c|c|c|c|c|c|c|c|c|}
\hline & $A D S$ & & & $m A D S$ & & & Marante & & \\
\hline $\begin{array}{l}\text { Sensory } \\
\text { deprivation } \\
\mathrm{n}(\%)\end{array}$ & 0.070 & $\begin{array}{l}-0.060- \\
0.20\end{array}$ & 0.297 & 0.27 & $\begin{array}{l}0.075- \\
0.46\end{array}$ & 0.007 & -0.036 & $\begin{array}{l}-0.23- \\
0.16\end{array}$ & 0.722 \\
\hline $\begin{array}{l}\text { History of } \\
\text { stroke n(\%) }\end{array}$ & 0.043 & $\begin{array}{l}-0.11- \\
0.19\end{array}$ & 0.591 & 0.06 & $\begin{array}{l}-0.17- \\
0.30\end{array}$ & 0.593 & 0.15 & $\begin{array}{l}-0.085- \\
0.38\end{array}$ & 0.213 \\
\hline $\begin{array}{l}\text { History of } \\
\text { dementia } \\
\mathrm{n}(\%)\end{array}$ & 0.055 & $\begin{array}{l}-0.07- \\
0.18\end{array}$ & 0.389 & 0.16 & $\begin{array}{l}-0.027- \\
0.35\end{array}$ & 0.094 & -0.08 & $\begin{array}{l}-0.27- \\
0.11\end{array}$ & 0.414 \\
\hline $\begin{array}{l}\text { MMSE } \\
\text { (pts/30) }\end{array}$ & -0.012 & $\begin{array}{l}-0.03- \\
0.03\end{array}$ & 0.109 & -0.024 & $\begin{array}{l}-0.05- \\
-0.002\end{array}$ & 0.029 & -0.005 & $\begin{array}{l}-0.027- \\
0.016\end{array}$ & 0.620 \\
\hline $\begin{array}{l}\text { Alcohol } \\
\text { abuse } \mathrm{n}(\%)\end{array}$ & -0.10 & $\begin{array}{l}-0.34- \\
0.14\end{array}$ & 0.435 & 0.01 & $\begin{array}{l}-0.34- \\
0.37\end{array}$ & 0.934 & 0.15 & $\begin{array}{l}-0.22- \\
0.51\end{array}$ & 0.426 \\
\hline \multicolumn{10}{|c|}{ Factors precipitating delirium } \\
\hline $\begin{array}{l}\text { Drug } \\
\text { withdrawal } \\
\mathrm{n}(\%)\end{array}$ & 0.59 & $\begin{array}{l}0.43- \\
0.74\end{array}$ & $<.001$ & 1.05 & $\begin{array}{l}0.82- \\
1.28\end{array}$ & $\hat{0} .001$ & 0.006 & $\begin{array}{l}-0.22- \\
0.23\end{array}$ & 0.959 \\
\hline $\begin{array}{l}\text { Surgery } \\
\mathrm{n}(\%)\end{array}$ & 0.02 & $\begin{array}{l}-0.09- \\
0.13\end{array}$ & 0.729 & -0.01 & $\begin{array}{l}-0.22- \\
0.20\end{array}$ & 0.923 & -0.023 & $\begin{array}{l}-0.29- \\
0.24\end{array}$ & 0.867 \\
\hline
\end{tabular}

In multivariate analysis, in the total group, the score of ADS was independently associated with female sex, with living in nursing home, with depression, with number of drugs on admission and with drug withdrawal $\left(F(5,1362)=51.95 ; R^{2}=0.16 ; p<0.001\right)$. This pattern explained $16 \%$ of the ADS score. mADS was independently associated with depression, with the number of drugs on admission and with drug withdrawal $\left(F(3,1372)=76.08 ; R^{2}=0.14 ; p<0.001\right)$. This pattern explained $14 \%$ of the ADS score. The score of Marante Scale was independently associated with living in nursing homes and number of drugs on admission $\left(F(2.641)=50.14 ; R^{2}=0.14 ; p<0.0001\right)$. This pattern explained $14 \%$ of the Marante Scale (Table 3). 
Table 3

Multivariate linear regression analysis of ADS, mADS and Marante Scale

\begin{tabular}{|llll|}
\hline & coeff & $95 \%$ Cl & $p$ \\
\hline ADS & & & \\
\hline Sex & -0.24 & $-0.36--0.12$ & $<0.0001$ \\
\hline Place of life & 0.14 & $0.016-0.28$ & 0.026 \\
\hline & & & \\
& & & 0.003 \\
\hline Depression & 0.18 & $0.061-0.29$ & $<0.001$ \\
\hline Drug withdrawal & 0.42 & $0.26-0.58$ & $<0.001$ \\
\hline Number of drugs on admission & 0.10 & $0.08-0.12$ & $<0.001$ \\
\hline mADS & & & $<0.001$ \\
\hline Depression & 0.38 & $0.21-0.55$ & $<0.0001$ \\
\hline Drug withdrawal & 0.78 & $0.55-1.01$ & \\
\hline Number of drugs on admission & 0.13 & $0.11-0.16$ & 0.018 \\
\hline Marante Scale & & & $<0.001$ \\
\hline Place of life & 0.19 & $0.027-0.35$ & \\
\hline Number of drugs on admission & 0.12 & $0.09-0.14$ & \\
\hline ADS: Anticholinergic Drug Scale - mADS: modified anticholinergic drug scale - Marante scale : & \\
\hline Muscarinic Acetylcholinergic Receptor Antagonist Exposure & & & \\
\hline
\end{tabular}

\section{Discussion}

We observed no difference in the anticholinergic burden of treatment at admission between delirium patients and the control group, despite the same prevalence of delirium as the other studies ${ }^{4}$. Our results confirmed previous studies ${ }^{16,24,27}$, while including a larger number of patients using scales based on comprehensive lists of anticholinergic drugs compared to other scales ${ }^{27}$.

These results can be explained by several factors. Firstly, the anticholinergic burden estimated by the scales used is low, which limits its effect on treatment as a predisposing factor for delirium, compared to other factors associated with delirium in multivariate analysis, such as male sex history of dementia, drug withdrawal and surgery, as already described ${ }^{2,5}$. Similarly, Passina et al. found that anticholinergic drugs increased the risk of delirium because of the cumulative effect, but this effect disappeared in the multivariate analysis after adjusting for dementia and malnutrition ${ }^{26}$. 
We also believe that the anticholinergic load assessed by ADS, mADS and Marante Scale underestimates the overall treatment of our elderly impatients: indeed, our analysis was based on the patient's usual treatment on admission and did not take into account the possible anticholinergic load administered in hospital. We also observed that these scales do not assess the anticholinergic load in the same way: for example, the ADS only assesses the anticholinergic potency of the drugs, whereas the mADS and the MARANTE Scale combine the anticholinergic potency with the dose of the drug. Moreover, they do not necessarily consider the marketing of new drugs. For instance, MARANTE Scale lists only 41 drugs out of the 100 drugs in the Duran et al. reference list ${ }^{15}$. Finally, the number of patients taking anticholinergic drugs users was lower than that found in the study by Rigor et al., i.e., $49 \%$ versus $72.7 \%{ }^{28}$.

Other studies have shown a positive association between delirium and anticholinergic burden ${ }^{22,26,29}$. This discrepancy may result from the great heterogeneity of the studies included in the literature reviews, whether due to the characteristics of the study (delirium is rarely the primary objective of the study), the study population (number of patients included, settings, age) or the scale used, the most commonly used scales being $A C B$ and $A D S^{16,24,26,28}$. According the litterature, only one study has analyzed modified $\operatorname{ADS}^{22}$ and two other have evaluated MARANTE scale ${ }^{14,30}$, which make it difficult to compare. In a recent study comparing 16 anticholinergic burden scales, Anticholinergic Cognitive load scale and ADS were considered to be the scales with the best inter-score agreement, with an inter-score correlation coefficient of 0.82 . The performance of the scales varied according to the characteristics of the population studied. The main pitfall was a wide variation in the estimation of the average daily dose and anticholinergic potency of the drugs, which varied considerably from one list to another, as we have observed ${ }^{31}$. Two recent reviews have evaluated the association between anticholinergic burden and clinical course, showing divergent results, due to the type of scale, the type of patients and the retrospective or prospective nature of the studies included $^{12,15}$.

In our study, none of the three scales was associated with length of stay, intra-hospital mortality, or one-year mortality. Only ADS and mADS scales in the control group were associated with intra-hospital mortality (respectively $\mathrm{p}=0.029$ and 0.049 ).

On the other hand, we have observed an association between anticholinergic burden according to ADS and mADS and female sex, which might be explained by the presence of drugs treating urinary incontinence that affects women more frequently.

Similarly, we observed an association between anticholinergic burden and living in nursing homes, which may be explained by a greater polypharmacy and an increased prescription of psychotropic drugs compared to people living at home, as described in the literature ${ }^{32}$. The association of anticholinergic burden and depression could be explained by the fact that antidepressants and benzodiazepines are the most prevalent drugs in anticholinergic burden scales. However, we believe that the diagnosis of depression may have been overestimated as it is sometimes determined by the presence of an antidepressant in the intake treatment.

Our study presents some strengths. 
The study took place in acute care medical and surgical services for comorbid and multi-medicated elderly people, representative of the frail geriatric population.

In addition, it included a large cohort over a five-years period, allowing for possible variations in medical conditions during hospitalization.

To our knowledge, this study is the first to compare the anticholinergic burden of two groups of older hospitalized patients with and without delirium according to three anticholinergic scales, including a scale validated on a Belgian population, the MARANTE Scale.

However, Marante Scale had a fairly good reliability with the ADS, which is more widely used in the literature. At least, it still needs to be studied on other populations and in other contexts. In addition, the modified version of the ADS did not add accuracy to detect a higher risk of delirium, which has not been described above.

The study has also some weaknesses. It is a single-center study, and methodologically limited

by its retrospective nature. This may explain why many factors associated with delirium could not be identified, including precipitating factors, limiting the interpretation of the lack of association between delirium and the anticholinergic burden.

Currently, anticholinergic scales are not yet standardized. They remain imprecise in drug categorization and do not consider inter-individual pharmacokinetic variability, as suggested by several systematic reviews ${ }^{33,34}$. Moreover, some scales such as ADS may have a "plateau" effect due to muscarinic receptor saturation or mode of action: Kersten et al. suggested that there is no increase in side effects when the anticholinergic burden is greater than $3^{35}$.

In addition, a few studies have hypothesized that ADS would be a better predictor of peripheral anticholinergic effects (e.g., dry mouth, constipation) than central effects, such as delirium and cognitive decline $\mathrm{e}^{16,34,35}$.

\section{Conclusions}

Regardless of the scale used, we have not demonstrated a significant association between the anticholinergic burden of treatment on admission and the onset of delirium during hospitalization. Nor was the anticholinergic load associated with length of stay, intra-hospital mortality and one-year mortality. All three scales highlighted risk groups for which anticholinergic drugs should be avoided such as women and institutionalized patients. On this basis, we do not recommend the use of these anticholinergic scales in clinical practice

to predict delirium in elderly impatients. Further prospective studies are needed to establish a relationship between anticholinergic burden and delirium.

\section{Abbreviations}


Anticholinergic Burden

ADS

Anticholinergic Drug Scale

mADS

modified Anticholinergic Drug Scale

MARANTE scale

Muscarinic Acetylcholinergic Receptor ANTagonist Exposure

SAA

Serum Anticholinergic Activity

GILT

Geriatric Internal Liaison team

CAM

Confusion Assessment Method

MMSE

Minimal Mental State Examination

GDS

Geriatric Depression Scale

CIRS-G

Cumulative IIIness Rating Scale-Geriatric

ADL

Activities of Daily Living

\section{Declarations}

Ethics approval and consent toparticipate: the study was conducted at the Erasme University Clinics in Brussels between January 2014 and June 2019 after approval of the institutional ethical committee (August $6^{\text {th }}$, reference $\left.\mathrm{P} 2019 / 379\right)$.

Consent for publication: Not Applicable

Availability of data and materials: the datasets generated during and/or analyzed during the current study are available from the corresponding author on reasonable request.

Competing interests: the authors have no potential conflict of interest to disclose.

Funding: No funding was used for this study

Author's contributions: De Breucker: study concept and design. GOY and Epoupa: relevant data collection; De Breucker, GOY and Epoupa: Data analysis and interpretation. GOY and De Breucker: drafting and preparing the manuscript. All: interpretation of data and revision of the manuscript. All authors read and approved the final manuscript. 
Aknowledgments: The authors would like to thank the geriatric internal liaison team (GILT) for helping collect data.

\section{References}

1. Lewis G. Diagnostic and statistical manual of mental disorders, 4th edn. Am Psy Ass. 1994;651-652. DOI: 10.1017/S0033291700035765

2. Kean J, Ryan K. Delirium detection in clinical practice and research: critique of current tools and suggestions for future development. J of Psychosom Research. 2008;255-259. DOI: 10/1016/j.jpsychores.2008.05.024

3. O'Keeffe S, Lavan J. The prognostic significance of delirium in older hospital patients.J Am Geriatr Soc. 1997;2:174- DOI:10.1111/J.15325415.1997.TB04503.X

4. Inouye SK. Delirium in older persons. N Engl J Med. 2006;354:1157-1165. DOI:10.1056/NEJMra052321

5. Elie M, Cole M, Primeau F, Bellavance F. Delirium risk factors in elderly hospitalized patients. J Gen Intern Med. 1998;3:204-212. DOI:19.1046/J.15251497.1998.00047.x

6. Inouye SK, Charpentier PA. Precipitating factors for delirium in hospitalized elderly persons.J Am Med Ass. 1996;11:852-857. DOI:10.1001/jama.1996.03530350034031.

7. Waymire JC. Acetylcholine Neurotransmission, Section 1, Chapter11. Neuroscience online: An Electronic Textbook for the Neurosciences.1997. https://nba.uth.tmc.edu/neuroscience. Accessed 1997.

8. Maldonado JR. Neuropathogenesis of delirium: review of current etiologic theories and common pathways. Am J Geriatr Psych. 2013;12:1190-1222. D0I:10.1016/j.jagp.2013.09.005

9. Bostock CV, Soiza RL, Mangoni AA. Association between prescribing of antimuscarinic drugs and antimuscarinic adverse effects in older people. Exp Rev Clin Pharmacol. 2010;4:442-452.

DOI:10.1586/ECP.10.34

10. Lopez-Alvarez J, Sevilla-Llewellyn-Jones J, Aguera-Ortiz L. Anticholinergic drugs in geriatric. Front Neurosc. 2019;13:1309-1324. DOI:10.3389/fnins.2019.01309

11. Mebarki S, Trivalle C. Assessment scales for the anticholinergic effects of drugs. Neur Psych Ger. 2012;69:131-138. DOI:10.1016/j.npg.2012.03.002

12. Cardwell K, Hugues CM, Ryan C. The association between Anticholinergic Medication Burden and Health Related Outcomes in the 'Oldest Old': A Systematic Review of the Literature. Drugs Aging. 2015;32:835-48. DOI:10.1007/s40266-015-0310-9

13. Carnahan RM, Lund BC, Perry PJ, Pollock BG, Culp KR. The anticholinergic drug scale as a measure of drug-related anticholinergic burden: associations with serum anticholinergic activity. J Clin Pharmacol 2006;46:1481-1486. DOI:10.1177/0091270006292126

14. Klamer TT, Wauters M, Azermai M, Duran C, Christiaens T, Elseviers M, Vander Stichele R. A novel scale linking potency and dosage to estimate anticholinergic exposure in older adults: The Muscarinic Acetylcholinergic Receptor ANTagonist Exposure Scale. Basic Clin Pharmacol Toxicol. 2016;6:582-590. DOI:10.1111/bcpt.12699 
15. Welsh TJ, Van der wardt V, Ojo G, Gordon AL, Gladman JRF. Anticholinergic Drug Burden Tools / Scales and Adverse Outcomes in Different Clinical Settings: A Systematic Review of reviews. Drugs Aging. 2018;6:523-538. DOI:10.1007/s40266-018-0549-Z

16. Campbell N, Boustani M, Limbil T, Ott C, Fox C, Maidment I, Schubert CC, Munger S, Fick D, Miller D, Gulati R. The cognitive impact of anticholinergics: a systematic review. Clin Interv Aging. 2009;4:225233. DOI: $10.2147 /$ cia.s5358

17. Inouye SK, Van Dyck CH, Alessi CA, Balkin S, Siegal AP, Horwitz RI. Clarifying confusion: the confusion assessment method. A new method for detection of delirium. Ann Intern Med. 1990;12: 941-948. DOI:10.7326/00034819-113-12-941

18. Linn BS, Linn MW, Gurel L. Cumulative illness rating scale. J Am Geriatr Soc. 1968;5: 622-626. DOI:10.111/j.1532-5415.1968.tb02103.x

19. Katz S, Ford AB, Moskowitz RW, Jackson BA, Jaffe MW. Studies of illness in the aged. The index of ADL: a standardized measure of biological and psychological function. J Am Med Assoc. 1963;12: 914919. DOI:10.1001/jama.1963.03060120024016

20. Yesavage JA, Brink TL, Rose TL, Lum O, Huang V, Adey M, Leirer VO. Development and validation of a geriatric depression scale: a preliminary report. J psych res. 1982-1983;1:37-49. DOI: 10.1016/00223956(82)90033-4

21. Folstein, MF, Folstein SE, Mc Hugh PR. "mini-mental state": A practical method for grading the cognitive state of patients for the clinician. J psychiatr research. 1975;3:189-198. DOI:10.1016/00223956(75)90026-6

22. Naja M, Zmudka J, Hannat S, Liabeuf S, Serot JM, Jouanny J. In geriatric patients, delirium symptoms are related to the anticholinergic burden. Geriatrics and gerontology international. 2016;4:424-431. DOI: 10.1111/GGI.12485

23. Duran CE, Azermai M, Vander Stichele RH. Systematic review of anticholinergic risk scales in older adults. Eur J clin Pharmacol. 2013;7: 1485-1496. DOI:10.1007/s00228-013-1499-3

24. Moorey HC, Zaidman S, Jackson TA. Delirium is not associated with anticholinergic burden or polypharmacy in older patients on admission to an acute hospital: an observational case control study. BMC geriatrics. 2016;16:162-168. DOI: 10.1186/s12877-016-0336-9

25. Lukkanen MJ, Uusvaara J, Laurila JV, Strandberg TE, Raivio MM, Tilvis RS, Pitkala KH. Anticholinergic drugs and their effects on delirium and mortality in the elderly. Dement geriatr cogn dis extra. 2011;1:43-50. DOI:10.1159/000322883

26. Passina L, Colzani L, Cortesi L, Tettamanti M, Zambon A, Nobili A, Mazzone A, Mazzola P, Annoni G, Bellelli G. Relation between Delirium and Anticholinergic Drug Burden in a Cohort of Hospitalized Older Patients: An Observational Study. Drugs Aging. 2019;1:85-91. DOI: 10.1007/s40266-018-0612-9

27. Gaudreau JD, Gagnon P, Harel F, Roy MA, Tremblay A. Psychoactive Medications and Risk of delirium in Hospitalized Cancer patients. J Clin Oncol. 2005;27: 6712-8. DOI: 10.1200/JC0.2005.05.140

28. Rigor J, Rueff Rato I, Ferreira PM, Pereira R, Ribeiro C, Teixeira D, Mesquita Oliveira P, Mafalda Silva A, Pereira S, Costa I, Ferreira P, Sequeira M, Montero Soares M, Martins mendes D. Prehospital 
Anticholinergic Burden is associated With Delirium but Not With Mortality in a Population of Acutely III Medical Patients. J Am Med Dir Assoc. 2014;4: 481-485. DOI: 10.1016/J.JAMDA.2019.12.018

29. Zimmerman KM, Salow M, Skarf LM, Kostas T, Paquin A, Simone MJ, Rudolph J. Increasing anticholinergic burden and delirium in palliative care inpatients. Palliat Med. 2014;4:335-341. DOI:10.1177/0269216314522105

30. Wauters M, Klamer T, Elseviers M, Vaes B, Dalleur O, Degryse J. Anticholinergic Exposure in a cohort of adults Aged 80 years and over: Association of the MARANTE scale with Mortality and Hospitalization. Basic Clin Pharmacol Toxicol. 2017;6:591-600. DOI: 10.1111/bcpt.12744

31. Lozano Ortega G, Johnson K, Cheung A, Wagg A, Campbell N, Dmochowski R, Ng D. A review of published anticholinergic scales and measures and their applicability in database analyses. Arch Gerontol Geriatr. 2020;87: 103885. DOI: 10.1016/j.archger.2019.05.010

32. Janus S, Van Manen J, ljzerman M, Zuiderma S. Psychotropic drug prescriptions in Western European nursing homes. Intern Psychoger. 2016;1:1775-1790. DOI:10.1017/S1041610216001150

33. Salahudeen MS, Duffull SB, Nishtala PS. Anticholinergic burden quantified by anticholinergic risk scales and adverse outcomes in older people: a systematic review. BMC Geriatr. 2015;15:31-35. DOI: $10.1186 / s 12877-015-0029-9$

34. Mayer T, Haefeli WE, Seidling HM. Different methods, different results-how do available methods link a patient's anticholinergic load with adverse outcomes? Eur J Clin Pharmacol. 2015;11:1299-314. DOI: 10.1007/s00228-015-1932-x

35. Kersten H, Molden E, Willumsen T, Zngedal K, Wyller TB. Higher anticholinergic drug scale (ADS) scores are associated with peripheral but not cognitive markers of cholinergic blockade. Cross sectional data from 21 Norwegian nursing homes: Association between high ADS scores and anticholinergic symptoms in the elderly. Br J Clin Pharmacol. 2013;3:842-849. DOI: 10.1111/j.1365-2125.2012.04411.x

\section{Figures}




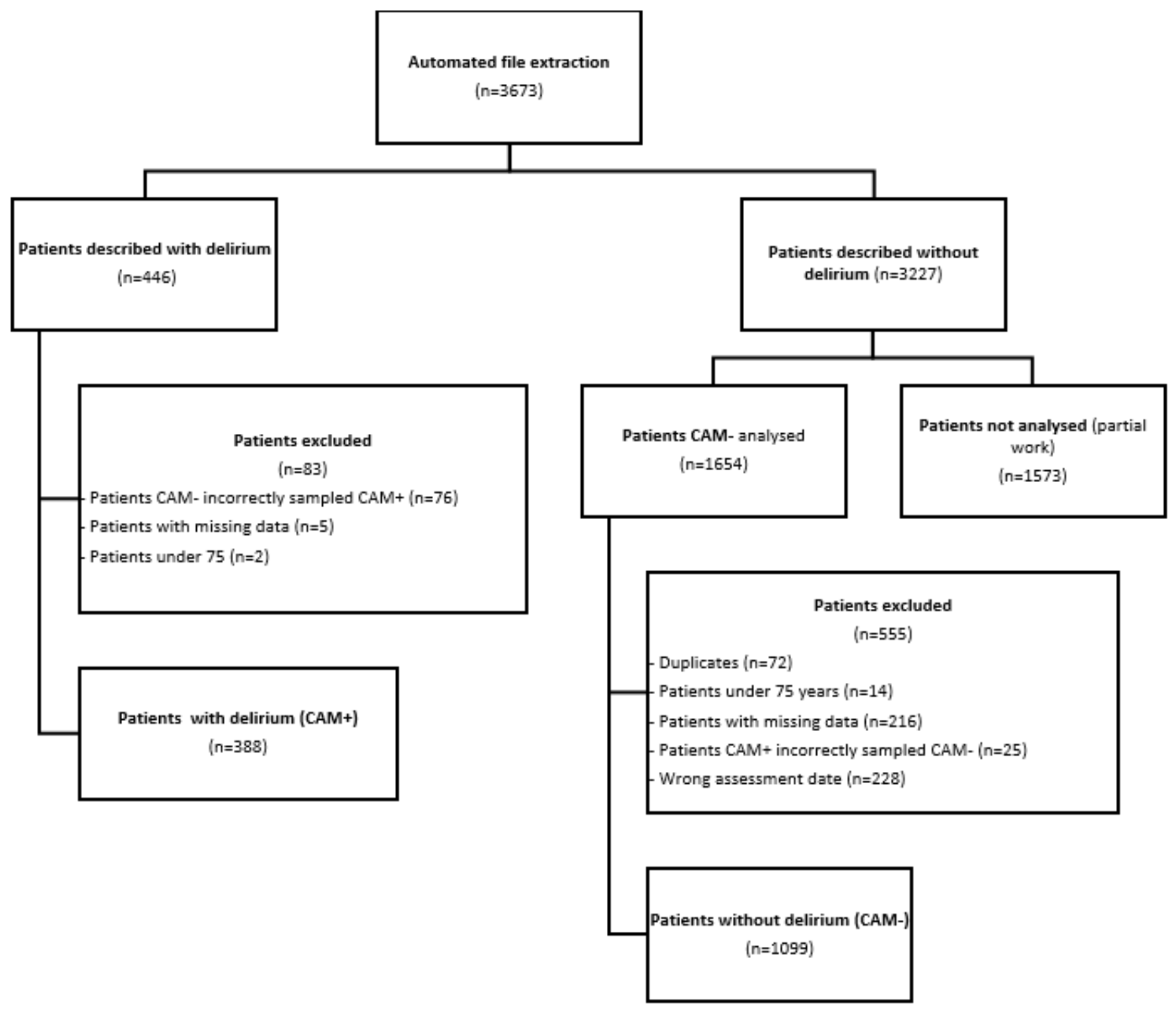

Figure 1

Flow chart of study participants 